\title{
Lead Drug Monitor
}

National Cancer Institute

\section{Source}

National Cancer Institute. Lead Drug Monitor. NCI Thesaurus. Code C51831.

The primary individual who over a period of time checks on and maintains continuous observation of state, condition, situation, or process relating to substances intended for use in diagnosis, cure, mitigation, treatment, or prevention of disease as a check on output, efficiency, conduct, etc. and warns of faults, or gives advice and instruction by way of reporting or caution. 